Do people travel with their preferred travel mode?

Analysing the extent of travel mode dissonance and its effect on travel satisfaction

\author{
Jonas De Vos \\ Geography Department \\ Ghent University, Belgium \\ Krijgslaan 281 (S8), 9000 Gent, Belgium \\ E-mail: jonas.devos@ugent.be
}




\title{
Do people travel with their preferred travel mode? Analysing the extent of travel mode dissonance and its effect on travel satisfaction
}

\begin{abstract}
Numerous studies have indicated that travel mode choice is affected by travel-related attitudes. A positive stance towards a certain travel mode increases the probability that people will choose this mode for a particular trip. However, not a lot of studies have analysed whether people actually choose their preferred travel mode. In this paper we will look at whether respondents with a preference for car use, public transport use, cycling and walking will actually use these modes. Furthermore, we also analyse whether respondents who use their preferred travel mode (i.e., consonant travellers) are more satisfied with their trips compared to respondents travelling with a non-preferred travel mode (i.e., dissonant travellers). Results from this study, analysing leisure trips of 1,656 respondents from the city of Ghent (Belgium), indicate that about half of the respondents chooses a non-preferred travel mode and that dissonant travellers can be mainly found within public transport users and least within cyclists, partly due to relatively low levels of public transport attitudes and high levels of cycling attitudes. Furthermore, travel mode dissonance seems to have an important impact on travel satisfaction. Consonant travellers have above average travel satisfaction levels, independent of the used travel mode, while dissonant travellers (except dissonant pedestrians) have below average travel satisfaction levels. This suggests that using a preferred travel mode has at least an equally important impact on travel satisfaction than the chosen travel mode itself.
\end{abstract}

Keywords: Travel behaviour; Travel mode choice; Travel attitudes; Travel mode preferences; Travel satisfaction

\section{Introduction}

Since attitudes are generally thought to play an important role in people's behaviour, numerous travel behaviour studies have incorporated attitudes into their analysis. ${ }^{1}$ Although some of them date back to the 1970s (e.g., Dobson et al., 1978; Tardiff, 1977), most of these studies are more recent and are often based on the theory of planned behaviour (Ajzen, 1991). According to this theory, attitudes are an important variable explaining people's intention to perform a given behaviour. Since the 1990s a large amount of studies have therefore tried to explain travel behaviour - and travel mode choice in particular - with the help of travel-related attitudes (e.g., Bagley and Mokhtarian, 2002; Bamberg et al., 2003; Cao et al., 2009; Handy et al., 2005; Kitamura et al., 1997). Besides rather strong effects from mode-specific attitudes on the frequency of using that mode (e.g., Beirão and Cabral, 2007; Heinen et al., 2011; Kroesen et al., 2017; Molin et al., 2016), also other types of travel-related attitudes can affect travel behaviour. Studies have shown that positive attitudes towards the environment discourage car use (Anable, 2005), while people with a positive

\footnotetext{
${ }^{1}$ An attitude can be defined as the degree of a favourable or unfavourable evaluation or appraisal of a certain object, person or behaviour (definition based on Ajzen, 1991; Eagly and Chaiken, 1993; Gärling et al., 1998; Van Acker et al., 2010). In this study, a mode-specific attitude can be described as the degree of positive/negative appraisal of the use of a certain travel mode, while a travel mode preference refers to a greater liking for a certain mode - or certain modes - over one or more other modes.
} 
stance towards travel itself (e.g., people valuing travel time) are mostly engaged in trips with above average trip duration and distance (De Vos and Witlox, 2016). Recent studies also show that people with a positive stance towards waiting frequently walk, cycle or use public transport (Mishra et al., 2015), while positive attitudes towards multitasking seem to result in a higher value of travel time (Ettema and Verschuren, 2007), an increased chance of train use and a decreased propensity of using the car or local public transport (i.e., bus/subway) (Malokin et al., 2015). Some studies also claim that these travel-related attitudes influence travel behaviour indirectly, through the residential location choice. People might try to select themselves in neighbourhoods facilitating the use of their preferred travel mode (e.g., Cao et al., 2009; Handy et al., 2005; Schwanen and Mokhtarian, 2005). Some studies have also indicated that travel-related attitudes and mode choice are mutually dependent on each other and that attitudes both affect, and are affected by, choices (Dobson et al., 1978; Golob, 2001; Kroesen et al., 2017; Tardiff, 1977).

However, attitudes might not always predict behaviour. Such a discrepancy between attitudes and behaviour (often referred to as a value-action gap (e.g., Blake, 1999; Kollmuss and Agyeman, 2002)) can be explained by the presence of subjective norms (perceived social pressure to engage or not engage in the behaviour) and perceived behavioural control (an individual's perceived ease or difficulty to perform a certain behaviour) (Ajzen, 1991), or by a lack of certain skills and the presence of certain barriers (de Vries et al., 1988). In travel behaviour studies, the built environment is often seen as an important potential barrier in the choice of a certain travel mode. People living in a suburban-style neighbourhood, for instance, might be forced to use motorised travel modes as destinations might be outside walking and cycling distance (e.g., Cervero and Kockelman, 1997; Ewing and Cervero, 2010). Furthermore, due to the repetitive and stable character of certain trips (especially commute trips) it is possible that travel mode choice has become habitual and is no longer based on attitudes and intentions, but mainly on past behaviour (Aarts et al., 1998; Bamberg et al., 2003; Gärling and Axhausen, 2003; Verplanken et al., 1997). A dissonance between attitudes and behaviour receiving a considerable amount of attention in travel behaviour studies is what is referred to as residential dissonance. Residential dissonance occurs when people choose to live in a certain neighbourhood which does not match with their travel and residential preferences (possibly caused by budgetary constraints or varying preferences within households). Since the residential location does not encourage the use of the preferred travel mode, dissonant residents are - to a certain extent - forced to travel with non-preferred travel modes (De Vos et al., 2012; Kamruzzaman et al., 2013; Schwanen and Mokhtarian, 2005), resulting in trips being perceived relatively negative (De Vos et al., 2016). Although some of the numerous travel behaviour studies focussing on attitudes and mode choice have indicated that travel attitudes and travel mode choice are not always congruent (e.g., Molin et al., 2016), a possible dissonance between travel mode preference and travel mode choice has not yet been analysed thoroughly.

According to the cognitive dissonance theory of Festinger (1957), a dissonance between attitudes and behaviour can result in feelings of discomfort, or dissatisfaction. However, such an effect of dissonance on satisfaction levels has not yet been clearly analysed in travel behaviour studies. Although over the past decade numerous studies have indicated that travel satisfaction (i.e., experienced emotions during - and cognitive evaluations of - trips) is greatly affected by the chosen travel mode (e.g., De Vos et al., 2016; Legrain et al., 2015; Morris and Guerra, 2015; Páez and Whalen, 2010; St-Louis et al., 2014), only a limited amount of studies have also looked at possible 
effects of travel mode attitudes/preferences on travel satisfaction levels. A positive attitude towards a certain mode seems to have a positive effect on travel satisfaction when using that mode (De Vos et al., 2016; St-Louis et al., 2014; Ye and Titheridge, 2017). ${ }^{2}$ This seems to suggest that when people travel with their preferred travel mode, travel satisfaction levels will be higher than when people (are forced to) travel with a non-preferred travel mode.

Since a potential dissonance between travel mode preference and travel mode choice - and its possible effect on travel satisfaction - has not been analysed thoroughly in previous studies, the analysis of these relationships will be the focus of this paper. In this study - based on leisure trips of 1,656 residents of the city of Ghent (Belgium) - we will analyse (i) the relationship between modespecific attitudes and the use of that mode, (ii) to which extent respondents use their preferred travel mode, based on a comparison of mode-specific attitudes towards four different travel modes, and (iii) whether respondents travelling with their preferred travel mode (i.e., consonant travellers) have higher levels of travel satisfaction compared to respondents using a non-preferred travel mode (i.e., dissonant travellers). Doing so, we want to create new insights into the links between attitudes, mode choice and travel satisfaction. This paper is organised as follows. Section 2 discusses possible causes and outcomes of travel mode dissonance. Section 3 explains the used data and methods, while main results are provided in Section 4. Discussion and conclusion are provided in Section 5.

\section{Travel mode dissonance}

\subsection{Causes of travel mode dissonance}

There can be many reasons for a dissonance between travel mode preference and travel mode choice. In this paper we distinguish four elements which can result in choosing a travel mode which is not the preferred one: (i) a lack of travel-related skills, (ii) a lack of travel options, (iii) the presence of travel barriers, and (iv) the presence of travel habits. First of all, a lack of certain skills can restrict the use of certain travel modes. Some people have physical disabilities which can prevent them to drive a car, ride a bicycle or walk certain distances. Others might not feel at ease using a car or bike during peak hours, in bad weather conditions or at unknown places, or do not master the road code or finding one's way. Not (fully) understanding public transport routes and schedules and not knowing where and when to transfer might prevent people to use public transport (Flamm and Kaufmann, 2006; kaufmann et al., 2004). Second, travel options might also affect travel mode choice. A public transport stop with frequent and multiple bus, lightrail or train lines, which serves until late in the evening will encourage public transport use more than a public transport stop which only serves limited lines during peak hours. Furthermore, the quality of service attributes such as cleanliness, comfort, and punctuality are important elements affecting public transport ridership (e.g., Chen et al., 2011; dell'olio et al., 2011; Lai and Chen, 2011; van Lierop et al., 2018). People might also not be

\footnotetext{
${ }^{2}$ It should be noted that travel-related attitudes might also affect travel satisfaction directly, independent from the chosen travel mode. De Vos and Witlox (2016) and Ye and Titheridge (2017), for instance, indicate that people with a positive stance towards travel in general (e.g., people valuing travel time) have higher levels of travel satisfaction compared to people disliking travel (e.g., people finding travel time wasted time), and this for all travel modes. De Vos et al. (2016) and Ye and Titheridge (2017) also found that a positive stance towards a certain travel mode can also positively affect travel satisfaction when using another mode (e.g., a positive effect of pro public transport on satisfaction with walking trips), potentially caused by correlated mode-specific attitudes (e.g., people liking both public transport and walking). In this paper, we will not take into account this possible direct effect of travel-related attitudes on travel satisfaction.
} 
inclined to cycle if cycling infrastructure is missing or limited, even in case of short distances and positive cycling attitudes. Narrow sidewalks in bad conditions, on the other hand, will probably discourage people to walk (e.g., Saelens et al., 2003a, 2003b; Sallis et al., 2004). Third, some barriers might prevent people to use a certain travel mode. Car use requires having a driving license and having access to an insured and legitimate car. Cycling requires access to an operational bicycle. It goes without saying that high-income groups are less affected by these constraints than low-income groups. The presence of slopes or bad weather conditions might prevent people to walk or cycle. The built environment - and the residential neighbourhood in particular - can impose restrictions in the use of certain modes (e.g., Cervero and Kockelman, 1997; Ewing and Cervero, 2001, 2010). People residing in suburban or rural environments might not be able to walk, cycle or use public transport as destinations are often not within walking or cycling distance and their neighbourhood might not be (frequently) served by public transport. Congestion, car-free zones and limited parking space might serve as barriers for car use in city centres. Furthermore, time restrictions might limit active travel while financial restrictions can constrain car use. Finally, when circumstances remain relatively stable, past travel choices can contribute to the prediction of later travel behaviour. Since travel behaviour has a rather repetitive character (especially commute trips) it is possible that travel mode choice has become habitual and therefore mainly based on past behaviour and no longer on attitudes and preferences (Aarts et al., 1998; Bamberg et al., 2003; Gärling and Axhausen, 2003; Verplanken et al., 1997).

It can be argued that the absence of travel barriers and the presence of travel-related skills and travel options is closely related with motility (Flamm and Kaufmann, 2006; Kaufmann et al., 2004; Shliselberg and Givoni, 2018). This motility, or potential travel, refers to people's ability to travel in a desired way. For instance, having access to many transport resources (e.g., owning a car, living close to a public transport network) and having the knowledge and skills regarding their use often makes it possible to use the preferred travel mode when travelling to an out-of-home activity. High levels of motility might therefore increase the chance that travel mode choices are based on mode-specific attitudes. It has to be noted that the four above mentioned elements do not necessarily result in the choice of a non-preferred travel mode. For instance, not being able to ride a bike, having limited public transport options and having most destinations not within walking distance, might still result in using the desired mode if that person prefers to travel by car. Furthermore, habitual mode choice - although not based on attitudes/preferences - will not necessarily result in the choice of a nonpreferred mode, as this frequently used mode might perfectly be the preferred travel mode. Due to a plausible effect from mode choice on attitudes, it is also possible that the four above mentioned elements can affect travel mode preferences. For instance, a person not cycling due to low cycling skills and/or not living within cycling distance of most out-of-home activities is unlikely to develop a preference for cycling.

\subsection{Influence of travel mode dissonance on travel satisfaction}

Over the past decade, an increasing interest in the link between travel and well-being has resulted in studies analysing how satisfied people are with specific trips and travel in general (De Vos et al., 2013; Ettema et al., 2010; Lancée et al., 2017). Since satisfaction levels of a certain activity episode can be regarded as the outcome of a decision (Kahneman et al., 1997; Kahneman and Krueger, 2006), numerous recent studies analysed the effect of travel mode choice on travel satisfaction. People using public transport (bus in particular) seem least satisfied with their trips, while active travel 
results in the highest levels of travel satisfaction. Intermediate satisfaction levels are mostly found for car users (De Vos et al., 2016; Gatersleben and Uzzel, 2007; Handy and Thigpen, 2018; Lancée et al., 2017; Legrain et al., 2015; Mao et al., 2016; Mokhtarian et al., 2015; Morris and Guerra, 2015; Olsson et al., 2013; Páez and Whalen, 2010; Singleton, 2018; Smith, 2017; St-Louis et al., 2014; Ye and Titheridge, 2017; Zhu and Fan, 2018). It can be argued that trip satisfaction is not only affected by the chosen travel mode itself, but also by whether the travel mode choice was an outcome of mode-specific attitudes. If people are able to travel with their preferred travel mode it is likely that they will experience their trip more positively compared to when people are forced to travel with a non-preferred travel mode. This line of thought seems to be confirmed by recent studies indicating that mode-specific attitudes positively affect travel satisfaction when using these modes (De Vos et al., 2016; St-Louis et al., 2014; Ye and Titheridge, 2017).

In this study we introduce the concepts of travel mode consonance and travel mode dissonance. We argue that travel mode consonance occurs when travel mode choice is the outcome of mode-specific attitudes, i.e., when people travel with their preferred travel mode. Travel mode dissonance, on the other hand, occurs when travel mode choice is constrained by a lack of travel-related skills, a lack of travel options, the presence of travel barriers, and/or the presence of travel habits. In case of travel mode dissonance, people will no longer travel with their preferred travel mode, but will use a nonpreferred mode. We hypothesise that relatively high levels of travel satisfaction will be reached when people travel with their preferred travel mode (i.e., travel mode consonance). Relatively low levels of travel satisfaction would be reached when people travel with a non-preferred travel mode (i.e., travel mode dissonance). The extent of travel mode dissonance and its effect on travel satisfaction will be analysed in this study (Figure 1). 

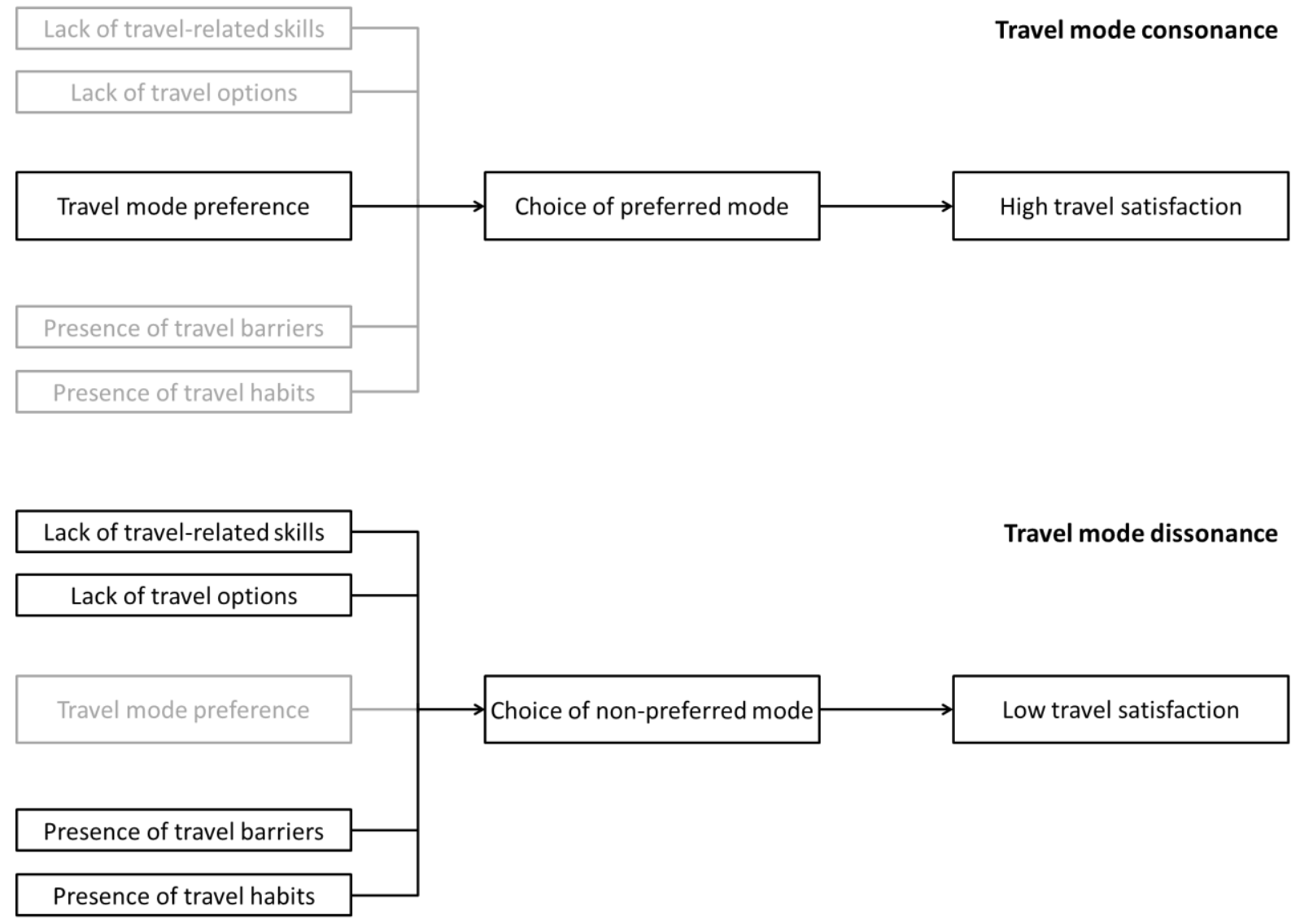

Figure 1: Hypothesised effect of travel mode consonance (top) and travel mode dissonance (bottom) on travel satisfaction. Black: dominant effects/factors; grey: subordinate effects/factors.

\section{Data and methods}

Data for this study is gathered from a 2012 Internet survey on residential location (choice), travel behaviour, travel satisfaction and well-being, which took place in the city of Ghent, Belgium $(260,000$ inhabitants). For this study we mainly use the following three elements of the survey: (i) travel mode choice of respondents' most recent leisure trip, (ii) satisfaction with these trips and (iii) attitudes towards car use, public transport use, cycling and walking. In total 27,780 invitations with a link to the survey were distributed by hand in five urban and seven suburban neighbourhoods within the city of Ghent. All households within the selected neighbourhoods received an invitation, covering about one fourth of all households in Ghent. The cover letter asked for an adult household member to complete the survey. Eventually, 1,807 persons completed the survey, of which 1,720 were retained after data cleaning. For this study we also removed respondents who did not indicate which travel mode they used to reach their most recent leisure activity and respondents using the train. Train users were removed as they only represent a small portion of the respondents (i.e., $2.8 \%$ ). ${ }^{3}$ In the end, 1,656 respondents were used in this study (Table 1). Although the recruitment method results in a rather low response rate (i.e., 6.5\%), respondents are roughly comparable to the population of the selected neighbourhoods in socio-economic and demographic terms (see De Vos et al., 2016). Since the main goal of this study is to achieve an analytical representation of relationships

\footnotetext{
${ }^{3}$ Since mode-specific attitudes were measured seperately for train users and bus/tram users, train and bus/tram users could not be grouped together.
} 
among multiple variables, it is important to have a large and sufficiently diverse sample (Groves, 1989). Since our sample size is relatively large, this allows us to estimate relationships with ample confidence.

Table 1. Socio-economic and demographic characteristics of the respondents $(N=1,656)$

\begin{tabular}{|c|c|}
\hline & $\%$ \\
\hline \multicolumn{2}{|l|}{ Personal characteristics } \\
\hline \multicolumn{2}{|l|}{ Age distribution } \\
\hline $18-30$ & 23.6 \\
\hline $31-45$ & 27.9 \\
\hline $46-60$ & 27.4 \\
\hline$>60$ & 21.1 \\
\hline \multicolumn{2}{|l|}{ Gender } \\
\hline Female & 45.8 \\
\hline Male & 54.2 \\
\hline \multicolumn{2}{|l|}{ Education } \\
\hline Low (lower than bachelor degree) & 22.8 \\
\hline High (bachelor degree or higher) & 77.2 \\
\hline \multicolumn{2}{|l|}{ Work status } \\
\hline Full time & 52.1 \\
\hline Part time & 16.1 \\
\hline Unemployed & 5.9 \\
\hline Student & 6.0 \\
\hline Retired & 19.6 \\
\hline \multicolumn{2}{|l|}{ Household characteristics } \\
\hline \multicolumn{2}{|l|}{ Household type } \\
\hline Single & 23.9 \\
\hline Single parent & 4.0 \\
\hline Couple without children & 38.3 \\
\hline Couple with children & 28.6 \\
\hline Other & 5.2 \\
\hline \multicolumn{2}{|l|}{ Household net income/month } \\
\hline Low $(<1,750$ euro) & 17.7 \\
\hline Average ( $1,750-3,499$ euro) & 49.1 \\
\hline High $(3,500+$ euro $)$ & 33.2 \\
\hline \multicolumn{2}{|l|}{ Household car possession } \\
\hline 0 & 14.5 \\
\hline 1 & 54.3 \\
\hline$>1$ & 31.2 \\
\hline \multicolumn{2}{|l|}{ Residential neighbourhood type } \\
\hline Urban & 56.9 \\
\hline Suburban & 43.1 \\
\hline
\end{tabular}

\subsection{Travel mode choice}

Respondents were asked to indicate which travel mode (car; bus/tram; bicycle or on foot) they used to reach their most recent out-of-home leisure activity (visiting family/friends; going out to restaurant, bar, club; going to forest, park, nature; participating in sports or cultural activity; recreational shopping). If they used more than one travel mode to reach their destination, they were asked to indicate the travel mode covering the longest distance. Leisure trips were chosen because of the assumption that mode choice (but also destination choice) is rather discretionary for these trips, especially compared to more mandatory commute trips. Using the most recent leisure trip, instead 
of for instance respondents' most common leisure trip, has the advantage that it is more convenient to measure travel satisfaction (see Section 3.3). However, the travel mode indicated by the respondents might not necessarily be the travel mode they usually use to reach leisure activities. Due to a relatively large sample size, however, respondents' indication of mode A while mode B is actually their generally used mode for leisure trips, will be largely counteracted by other respondents' indication of mode $B$, while mode $A$ is their most commonly used mode. Somewhat more than half of the respondents (i.e. 883 ; 53.3\%) travelled by car, 117 respondents $(7.1 \%)$ used public transport (bus/tram), 337 respondents (20.4\%) cycled and 319 respondents (19.3\%) walked to their most recent out-of-home leisure activity.

\subsection{Mode-specific attitudes}

Although a lot of studies have analysed the effect of travel-related attitudes on travel mode choice (and vice versa), we feel that most of these studies use rather general attitudes related with travel (e.g., attitudes towards the environment, residential preferences). In case studies analyse modespecific attitudes, variables relating to these attitudes are often factor-analysed, whereby the actual value of the original variable gets lost and the variable is being integrated in a factor which also represents other variables. This makes it impossible to compare attitudes towards different modes and to analyse whether people travel with their preferred travel mode. Some studies have incorporated certain questions representing a preference of one mode over another. Handy et al. (2005) and Cao et al. (2007) asked respondents to indicate to which extent they agree on three statements: I prefer to (i) bike/ (ii) walk/ (iii) take transit rather than drive whenever possible. However, these variables were factor analysed (in a pro walk/bike factor and a pro transit factor), making it impossible to fully capture travel mode preferences. Van Wee et al. (2002) on the other hand, used one question to measure people's mode preference: To which category do you belong?; providing the following possible answers: preference for car, preference for bicycle or preference for public transport. To the best of our knowledge, only three recent Dutch studies (Kroesen and Chorus, 2018; Kroesen et al., 2017; Molin et al., 2016), have constructed variables representing specific attitudes towards car use, cycling and public transport in a way that makes it possible to compare these attitudes. They asked (on a scale from 1 to 5) to which extent driving by car/cycling/using public transport is easy, relaxing, fun, healthy, safe, and environment-friendly, and created a scale for each mode - ranging from 6 to 30 - by summing up the items belonging to each mode. In an older study, Anable and Gatersleben (2005) used a similar approach by asking respondents to which degree (on a five-point scale) they find car use/public transport use/cycling/walking flexible, convenient, inexpensive, predictable, environment-friendly and healthy. However, this study did not sum up the scores on these attributes, whereby overall liking scores of the different travel modes were not compared.

In order to capture attitudes towards specific travel modes, we asked respondents which of the following sixteen positive aspects they link (yes/no) with the use of the four travel modes (car, public transport (bus/tram), cycling and walking): pleasant; good for image; environment-friendly; relaxing; comfortable; time saving; flexible; inexpensive; offering privacy; healthy; safe; reliable; possibility to perform activities during travel; enabling participation in preferred out-of-home activities; providing feelings of freedom; and finally whether or not respondents want to live in a neighbourhood 
stimulating car use/public transport use/cycling/walking ${ }^{4}$. We used the sum across these sixteen perceptions as measure for mode-specific attitudes. Doing so enables us to compare attitudes towards different modes, which would not be possible when measuring attitudes of various modes by different perceptions/statements and/or by using factor scores resulting from a factor analysis. Table 2 shows the average scores on the sixteen aspects for all four modes. On average, respondents link cycling most to the sixteen positive aspects, followed by walking and car use. Public transport is clearly least related with the sixteen positive aspects. These results seem to be in line with other studies stating that, on average, people prefer cycling and (if measured) walking most, followed by car use and least prefer to use public transport (Anable and Gatersleben, 2005; Kroesen et al., 2017; van Wee et al., 2002). The reason for these differences in travel mode attitudes/preferences is, however, unclear, and can also not be discovered with the available data in this study. The internal consistency of the sixteen items are good (Cronbach alpha's are $0.80,0.76,0.86$ and 0.81 for car use, public transport use, cycling and walking, respectively) indicating that the sixteen binary variables are well correlated with each other and that they measure the same construct, i.e., a positive attitude towards car use, public transport use, cycling and walking, respectively.

Table 2. average scores of positive elements linked to the use of various travel modes $(N=1,656)$

\begin{tabular}{lcccc}
\hline & Car use & PT use & Cycling & Walking \\
\hline Pleasant & 0.62 & 0.29 & 0.63 & 0.67 \\
Good for image & 0.20 & 0.15 & 0.54 & 0.34 \\
Environment-friendly & 0.00 & 0.32 & 0.86 & 0.77 \\
Relaxing & 0.17 & 0.12 & 0.67 & 0.66 \\
Comfortable & 0.76 & 0.14 & 0.22 & 0.18 \\
Time saving & 0.67 & 0.09 & 0.49 & 0.09 \\
Flexible & 0.70 & 0.05 & 0.63 & 0.36 \\
Inexpensive & 0.03 & 0.20 & 0.82 & 0.81 \\
Offering privacy & 0.76 & 0.02 & 0.32 & 0.28 \\
Healthy & 0.02 & 0.02 & 0.86 & 0.83 \\
Safe & 0.29 & 0.43 & 0.15 & 0.42 \\
Reliable & 0.56 & 0.15 & 0.60 & 0.66 \\
Possibility to perform activities during travel & 0.17 & 0.27 & 0.15 & 0.20 \\
Enabling participation in preferred out-of home activities & 0.73 & 0.16 & 0.46 & 0.25 \\
Providing feelings of freedom & 0.74 & 0.09 & 0.68 & 0.58 \\
Like to live in neighbourhood stimulating car/PT/cycl./walk. & 0.70 & 0.87 & 0.80 & 0.80 \\
\hline Total (max. 16) & 7.11 & 3.36 & 8.87 & 7.90 \\
\hline
\end{tabular}

It has to be noted that using (sixteen) binary variables can be seen as a limitation, as it results in a certain loss of information. Alternatively, five- or seven-point likert scales could have measured how respondents link certain positive aspects with the use of a specific travel mode, as has been done in a limited amount of previous studies (i.e., Anable and Gatersleben, 2005; Kroesen and Chorus, 2018; Kroesen et al., 2017; Molin et al., 2016). However, using sixteen (binary) variables has the advantage that a wide range of elements - that can be linked to the use of a certain mode - are captured, without imposing a sizeable respondents burden (which would be impossible when applying sixteen five- or seven-point scales for all four modes). It should be noted, however, that the highest amount of positive aspects linked to a certain mode might not necessarily represent the preferred mode. For

\footnotetext{
${ }^{4}$ In the survey this was respectively described as: A neighbourhood with good car accessibility/ good public transport services/ high-quality cycle lanes/ a lot of destinations within walking distance.
} 
instance, people might acknowledge that cycling is inexpensive, healthy, environment-friendly, etc., but still prefer to use the car (e.g., due to its convenience). Furthermore, some aspects possibly affecting the liking for a certain mode are only applicable to that specific mode (e.g., free-flow traffic and parking availability for car use; punctuality and smooth transfers for public transport use; and personal fitness levels and presence of high-quality walking/cycling infrastructure for active travellers), and can therefore not be taken into account in this study.

\subsection{Travel satisfaction}

In order to measure how satisfied respondents are with the trip to their most recent out-of-home leisure activity, we use the Satisfaction with Travel Scale (STS) (De Vos et al., 2015; Ettema et al., 2011; Friman et al., 2013). This scale asks respondents to indicate which emotions they experienced during the trip and how they evaluated this trip. Using the most recent (leisure) trip, instead of a commonly made (leisure) trip, has the advantage that recall bias is minimised. The STS uses two sets of three adjective pairs to measure the intensity, frequency and duration of positive and negative feelings during a trip. The two sets are specific combinations of valence and activation, i.e., negative deactivation - positive activation and negative activation - positive deactivation. The respective adjective pairs are bored - enthusiastic, fed up - engaged and tired - alert; and stressed - calm, worried - confident and hurried - relaxed. The STS measures cognitive evaluation through a set of adverse statements regarding the trip made (i.e., trip was the worst - best I can think of, trip was low - high standard and trip did not go well - went well). For all the nine scales, scores vary from -3 to 3 with a higher score implying higher satisfaction. Three factors (explaining $77.4 \%$ of total variance) can be extracted from the nine items using principal axis factoring and promax rotation: a factor referring to positive evaluation and two factors referring to positive emotions (positive deactivation and positive activation, respectively) (Table 3 ). Travel satisfaction levels differ considerably according to the chosen travel mode. Pedestrians have the highest average scores on the three factors (i.e., 0.16, 0.14 , and 0.14 , respectively), while public transport users have the lowest average factor scores (i.e., $-0.17,-0.17$, and -0.39 , respectively). Average factors scores of car users and cyclists are somewhat in between (i.e., respectively $-0.05,0.00$, and -0.01 for car users and $0.03,-0.06$, and 0.04 for cyclists).

Table 3. Factors for travel satisfaction $(N=1,656)$

\begin{tabular}{|c|c|c|c|}
\hline $\begin{array}{l}\text { Factor } \rightarrow \\
\text { Positive adjective/statement } \downarrow\end{array}$ & Positive evaluation & Positive deactivation & Positive activation \\
\hline Trip was best I can think of & 0.95 & & \\
\hline Trip went well & 0.77 & & \\
\hline Trip was high standard & 0.73 & & \\
\hline Calm & & 0.99 & \\
\hline Relaxed & & 0.87 & \\
\hline Confident & & 0.48 & \\
\hline Engaged & & & 0.88 \\
\hline Enthusiastic & & & 0.83 \\
\hline Alert & & & 0.45 \\
\hline
\end{tabular}

Note: Factor loadings between -0.25 and 0.25 have been suppressed to enhance readability.

\section{Results}

\subsection{Mode-specific attitudes and travel mode choice}


As indicated by Table 2, respondents link cycling most with positive aspects, followed by walking and car use. Public transport is clearly least related with the sixteen positive aspects. Figures 2 to 5 indicate that mode-specific attitudes are related with travel mode choice. Respondents linking a high amount of positive aspects to a certain travel mode have a higher chance of using that mode compared to respondents only linking a limited amount of aspects to this mode. For all travel modes, the average amount of positive aspects linked to a mode is significantly higher (at $p<0.05$ ) for people using that mode, compared to people using another mode (based on two-sample t-tests). It is striking that - on average - respondents who do not use the car, cycle or walk link more positive aspects to these respective modes compared to public transport users link to public transport use, indicating very low levels of liking for public transport use.

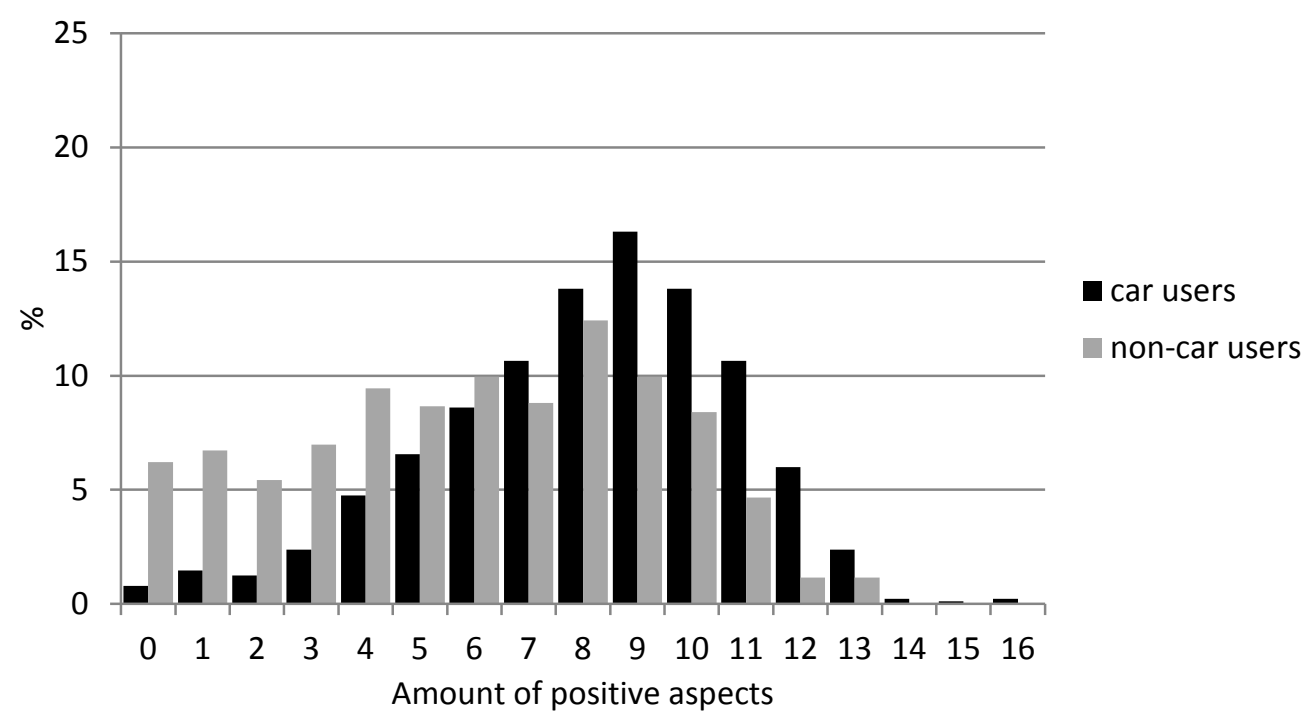

Figure 2: Amount of positive aspects linked to car use, for car users ( $n=883$, avg.: 8.13) and non-car users ( $n=773$, avg.: 5.94). For car users: st. deviation: 2.75 ; skewness: -0.50 ; kurtosis: 0.13

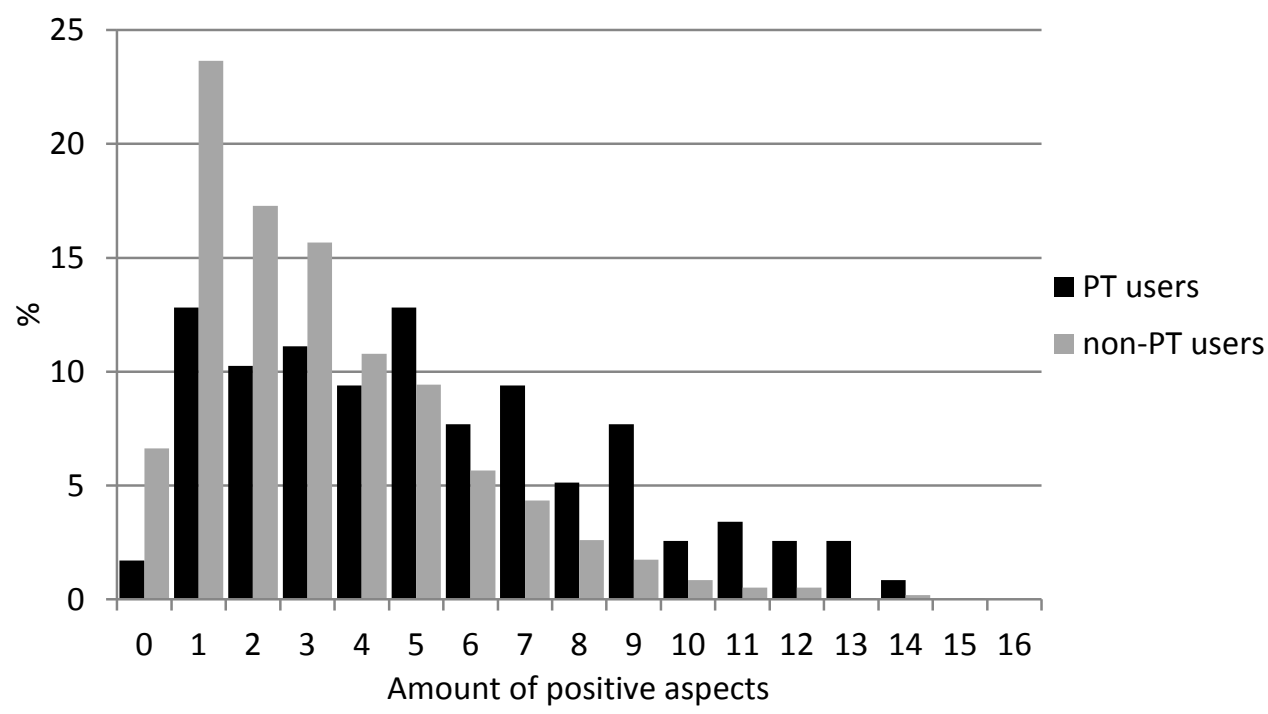

Figure 3: Amount of positive aspects linked to public transport use, for public transport users ( $\mathrm{n}=$ 117, avg.: 5.30) and non-public transport users ( $n=1,539$, avg.: 3.21). For public transport users: st. deviation: 3.40 ; skewness: 0.56 ; kurtosis: -0.45 . 


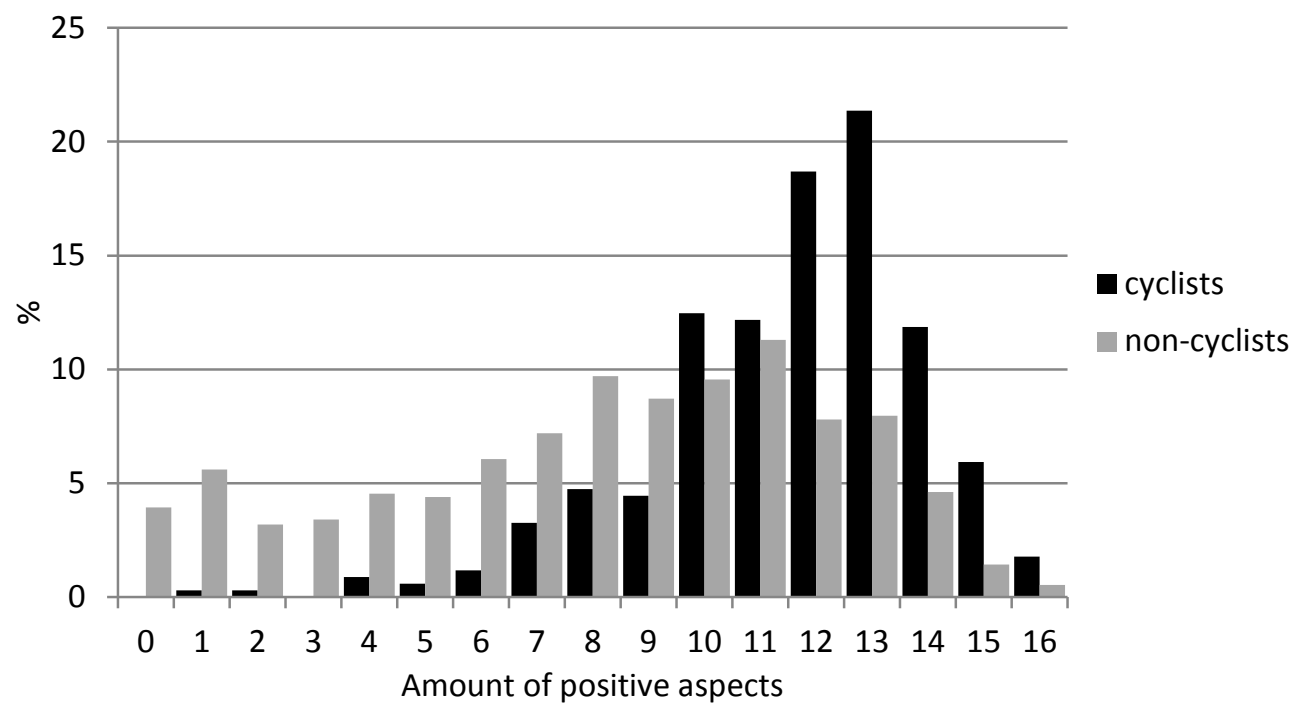

Figure 4: Amount of positive aspects linked to cycling, for cyclists ( $n=337$, avg.: 11.60) and noncyclists ( $n=1,319$, avg.: 8.17). For cyclists: st. deviation: 2.43; skewness: -1.02; kurtosis: 1.66 .

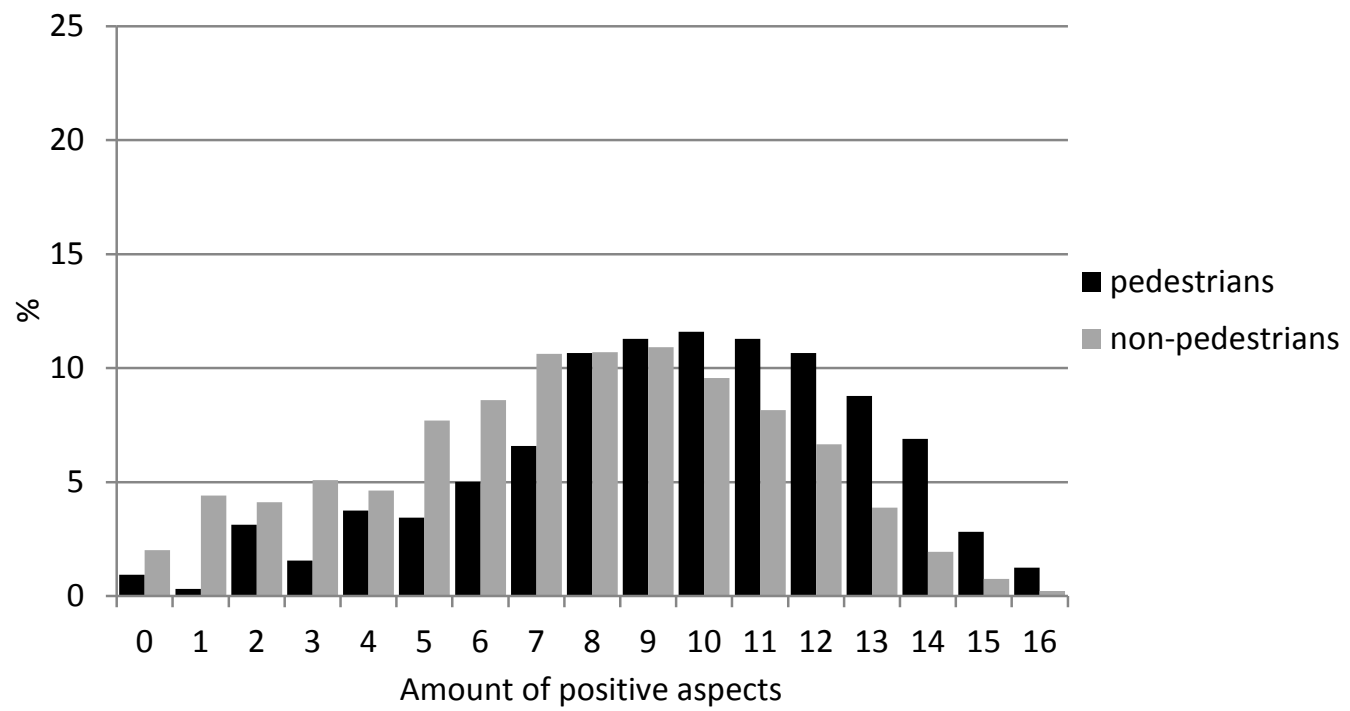

Figure 5: Amount of positive aspects linked to walking, for pedestrians ( $n=319$, avg.: 9.48) and nonpedestrians ( $n=1,337$, avg.: 7.53). For pedestrians: st. deviation: 3.39 ; skewness: -0.51 ; kurtosis: 0.14 .

Table 4 takes a closer look at attitudes towards non-chosen modes. Besides significant higher scores of respondents using a specific mode (compared to non-users), this table also indicates that attitudes towards other modes relate with the chosen mode. For instance, public transport users link significantly less positive aspects to cycling compared to car users and pedestrians. Pedestrians associate significantly more positive aspects with public transport use compared to car users and cyclists. For attitudes towards walking, we found significantly more positive aspects linked to this mode for cyclists compared to car users. Finally, no significant differences were found for car attitudes between public transport users, cyclists and pedestrians. Keeping some caution in mind, this seems to suggest that - to a certain extent - pedestrians like public transport use, public 
transport users dislike cycling and cyclists like to walk. Nevertheless, respondents still have the most positive attitude towards the chosen mode itself. These results are partly in line with the study of Molin et al. (2016), stating that attitudes are mainly congruent with travel mode use and that car users have a less positive stance towards public transport and cycling, compared to people using other modes.

Table 4. P-values of a one-way ANOVA with post-hoc multiple comparison analysis using the LSD method, analysing differences in positive aspects linked to car use, public transport use, cycling and walking according to the used travel mode (average scores between brackets; bold = significant at $p<$ 0.05)

\begin{tabular}{|c|c|c|c|c|c|c|c|}
\hline $\begin{array}{l}\text { Positive aspects linked } \\
\text { to car use }\end{array}$ & 1. & 2. & 3. & $\begin{array}{l}\text { Positive aspects linked } \\
\text { to public transport }\end{array}$ & 1. & 2. & 3. \\
\hline 1. Car users (8.13) & & & & 1. Car users (3.06) & & & \\
\hline 2. PT users (5.89) & 0.00 & & & 2. PT users (5.30) & 0.00 & & \\
\hline 3. Cyclists (5.73) & 0.00 & 0.62 & & 3. Cyclists (3.21) & 0.38 & 0.00 & \\
\hline 4. Pedestrians (6.19) & 0.00 & 0.35 & 0.06 & 4. Pedestrians (3.63) & 0.00 & 0.00 & 0.03 \\
\hline $\begin{array}{l}\text { Positive aspects linked } \\
\text { to cycling }\end{array}$ & 1. & 2. & 3. & $\begin{array}{l}\text { Positive aspects linked } \\
\text { to walking }\end{array}$ & 1. & 2. & 3. \\
\hline 1. Car users $(8.20)$ & & & & 1. Car users (7.31) & & & \\
\hline 2. PT users (6.93) & 0.00 & & & 2. PT users (7.63) & 0.34 & & \\
\hline 3. Cyclists (11.60) & 0.00 & 0.00 & & 3. Cyclists (8.07) & 0.00 & 0.25 & \\
\hline 4. Pedestrians (8.55) & 0.14 & 0.00 & 0.00 & 4. Pedestrians (9.48) & 0.00 & 0.00 & 0.00 \\
\hline
\end{tabular}

\subsection{Travel mode consonance and dissonance}

Based on the amount of positive elements linked to car use, public transport use, cycling and walking, we are able to subdivide the respondents according to their mode preference. The travel mode that is linked with the highest amount of positive elements given by a certain respondent is regarded as the preferred mode of that respondent. Due to the limited amount of elements that can be linked to various travel modes (i.e., 16), it is possible that respondents link an equal amount of positive elements to two or more travel modes resulting in a preference for more than one mode (in case that the equal amounts of elements are higher than the amount of elements linked to the other mode(s)). However, this should not be regarded as a drawback as it is possible that people have a preference for more than one mode. They might have positive attitudes towards two or three modes or they might have a negative stance towards a certain mode, being indifferent of which mode to use, as long as it is not that mode they dislike. In our sample, 1,424 (86.0\%) respondents have a preference for a single mode, while 232 respondents (14.0\%) have multimodal preferences.

Table 5 shows respondents' mode preference. Not surprisingly, a large share of the respondents (42.3\%) has a preference for cycling as, on average, most positive elements are linked with this travel mode. 386 respondents (23.3\%) prefer to use the car, while 296 respondents (17.9\%) have a preference for walking. It might seem rather surprising that more people have a preference for car use than for walking as - on average - more positive elements are linked to walking compared to car use. This can be partly explained by a relatively strong correlation between positive aspects linked to cycling and positive aspects linked to walking (pearson's correlation coefficient $=0.32$ ). ${ }^{5}$ As a result,

\footnotetext{
${ }^{5}$ Pearson's correlation coefficients (and $p$-values) for positive aspects linked to travel modes are: $-0.12(p=0.00)$ for car and public transport, $-0.17(p=0.00)$ for car and bike, $-0.06(p=0.02)$ for car and walking, $0.06(p=0.03)$ for
} 
respondents linking a considerable amount of positive aspects to walking, might also link the same amount or more positive aspects to cycling. This also results in a relatively large group of respondents $(6.0 \%)$ having a preference for both walking and cycling. Only a small share of the respondents $(2.5 \%)$ has a preference for public transport use, which is not surprising due to the low average amount of positive aspects linked to public transport use.

Based on the respondents' mode preference and the travel mode they chose to reach their most recent out-of-home leisure activity, the extent of travel mode dissonance can be measured. Table 5 shows how car users, public transport users, cyclists and pedestrians are distributed according to their preferred mode. We define consonant travellers as respondents using a preferred travel mode and dissonant residents as respondents using a non-preferred travel mode. Slightly more than half of the respondents (i.e., 849 respondents, 51.3\%) have chosen their preferred travel mode. Cyclists clearly have the highest share of consonant travellers; most cyclists (i.e., 87.2\%) have a preference for cycling. Somewhat more than half of the car users and pedestrians (i.e., $56.4 \%$ and $53.3 \%$, respectively) are dissonant, indicating that they have a preference for another mode. The highest level of dissonance can be found within the group of public transport users. Only $17.9 \%$ of public transport users has a preference for using public transport. This can be partly explained by the overall small share of respondents preferring public transport. Respondents with multimodal preferences travel more with their preferred travel mode compared to respondents with a preference for a single mode (i.e., $71.1 \%$ versus $48.0 \%$ ). The fact that the former group prefers more than one mode makes it relatively easy for them to travel with one of their preferred travel modes.

Table 5. Distribution of respondents according to their travel mode preference and chosen travel mode.

\begin{tabular}{lccccc}
\hline & Car users & PT users & Cyclists & Pedestrians & Total \\
\hline Car preference & 305 & 20 & 20 & 41 & 386 \\
Public transport preference & 19 & 16 & 1 & 5 & 41 \\
Cycling preference & 300 & 33 & 251 & 117 & 701 \\
Walking preference & 130 & 34 & 20 & 112 & 296 \\
\hdashline Car - PT preference & 1 & 2 & 0 & 1 & 4 \\
Car - cycling preference & 46 & 0 & 10 & 5 & 61 \\
Car - walking preference & 23 & 5 & 1 & 8 & 37 \\
PT - cycling preference & 1 & 0 & 0 & 1 & 2 \\
PT - walking preference & 1 & 2 & 0 & 3 & 6 \\
Cycling - walking preference & 46 & 4 & 29 & 20 & 99 \\
\hdashline Preference for 3 or more modes & 11 & 1 & 5 & 6 & 23 \\
(consonant - dissonant) & $(10-1)$ & $(1-0)$ & $(4-1)$ & $(6-0)$ & $(21-2)$ \\
\hline Total & 883 & 117 & 337 & 319 & 1,656 \\
\hline \multicolumn{1}{c}{ Consonant travellers } & & & & &
\end{tabular}

public transport and cycling, $0.24(p=0.00)$ for public transport and walking, and $0.32(p=0.00)$ for cycling and walking. 


\subsection{Travel satisfaction of consonant and dissonant travellers}

Since it can be argued that people choosing their preferred travel mode will be more satisfied with their trip compared to people using a non-preferred mode, we expect travel satisfaction levels to be higher for consonant travellers than for dissonant travellers. Table 6 indicates that consonant travellers experience more positive feelings during the trip and also evaluate this trip more positively compared to dissonant travellers, and this for all travel modes. For car users, public transport users and cyclists, the evaluation of the trip is significantly higher for consonant travellers than for dissonant travellers. Consonant cyclists are significantly more calm, relaxed and confident (i.e., positive deactivation) compared to dissonant cyclists, while consonant car users and public transport users are significantly more engaged, enthusiastic and alert (i.e., positive activation) compared to dissonant car and public transport users. Although consonant pedestrians have higher travel satisfaction scores than dissonant pedestrians, differences are not significant (at $p<0.05$ ). It is remarkable to see that for all modes, except walking, travel satisfaction scores are positive for consonant travellers and negative for dissonant travellers. This is also the case for public transport users, which have lower average levels of travel satisfaction compared to users of other travel modes. These low average levels of travel satisfaction can be explained by the relatively large group of public transport users with a preference for other modes (i.e., 82.1\%). For pedestrians we did not found negative travel satisfaction scores for dissonant travellers. Although not using their preferred travel mode, dissonant pedestrians seem to perceive their walking trip relatively positive, resulting in high average travel satisfaction scores of all pedestrians combined. ${ }^{6}$ Furthermore, it is also rather surprising that cyclists - having the most positive attitude towards the used mode - have rather average travel satisfaction scores. This can be mainly explained by the dissonant cyclists. Although this is a rather small group compared to consonant cyclists, they have very negative travel satisfaction scores, especially on the positive evaluation factor and the positive deactivation factor. This suggests that people who are forced to cycle do not like it at all. A possible explanation for this is that cycling is often perceived as a dangerous activity (e.g., Lorenc et al., 2008; Pooley et al., 2013), resulting in (dissonant) cyclists not being calm, relaxed and/or confident.

Table 6. Average travel satisfaction levels (i.e., factor scores) of consonant and dissonant travellers according to the used mode, and all users of the same mode combined.

\begin{tabular}{|c|c|c|c|c|c|c|c|}
\hline & \multicolumn{2}{|c|}{$\begin{array}{r}\text { Positive evaluation } \\
\text { Mode } \\
\text { total }\end{array}$} & \multicolumn{2}{|c|}{$\begin{array}{r}\text { Positive deactivation } \\
\text { Mode } \\
\text { total }\end{array}$} & \multicolumn{2}{|c|}{$\begin{array}{r}\text { Positive activation } \\
\text { Mode } \\
\text { total }\end{array}$} & $\mathbf{N}$ \\
\hline $\begin{array}{l}\text { Consonant car users } \\
\text { Dissonant car users }\end{array}$ & $\begin{array}{c}0.04 \\
-0.12 \\
\end{array}$ & -0.05 & $\begin{array}{c}0.03 \\
-0.03\end{array}$ & 0.00 & $\begin{array}{c}0.06 \\
-0.07\end{array}$ & -0.01 & $\begin{array}{l}385 \\
498\end{array}$ \\
\hline $\begin{array}{l}\text { Consonant PT users } \\
\text { Dissonant PT users }\end{array}$ & $\begin{array}{l}0.20 \\
-0.26\end{array}$ & -0.17 & $\begin{array}{c}0.02 \\
-0.21 \\
-0.21\end{array}$ & -0.17 & $\begin{array}{c}0.02 \\
-0.48\end{array}$ & -0.39 & $\begin{array}{l}21 \\
96\end{array}$ \\
\hline $\begin{array}{l}\text { Consonant cyclists } \\
\text { Dissonant cyclists }\end{array}$ & $\begin{array}{c}0.09 \\
-0.40 \\
-\end{array}$ & 0.03 & $\begin{array}{r}0.00 \\
-0.43 \\
-\end{array}$ & -0.06 & $\begin{array}{c}0.07 \\
-0.21\end{array}$ & 0.04 & $\begin{array}{c}294 \\
43\end{array}$ \\
\hline $\begin{array}{l}\text { Consonant pedestrians } \\
\text { Dissonant pedestrians }\end{array}$ & $\begin{array}{l}0.19 \\
0.14\end{array}$ & 0.16 & $\begin{array}{l}0.18 \\
0.11\end{array}$ & 0.14 & $\begin{array}{l}0.21 \\
0.08\end{array}$ & 0.14 & $\begin{array}{l}149 \\
170\end{array}$ \\
\hline
\end{tabular}

\footnotetext{
${ }^{6}$ A possible explanation for the high travel satisfaction levels of pedestrians is that pedestrians relatively often travel to positively experienced leisure activities (e.g., recreational shopping). As a high correlation exists between trip satisfaction and satisfaction with the leisure activity at the destination of the trip, it is plausible that pedestrians confound their trip with the mostly positively perceived leisure activity at the destination (see De Vos, 2018).
} 
Note: grey background: average scores of consonant and dissonant travellers are significantly different from each other at $p<0.05$ (based on two-sample t-tests)

Finally, apart from respondents being consonant or dissonant travellers, results also indicate that respondents with a preference for two or more travel modes do not have higher travel satisfaction levels compared to respondents with a preference for one mode, ${ }^{7}$ even though travel mode dissonance is lower for the former group. This could be explained by the fact that respondents with multimodal preferences have a somewhat - albeit non-significant (at $p<0.05$ ) - less positive attitude towards the used mode, compared to respondents with a preference for one mode (average amount of positive aspects linked to the used mode is 8.60 versus 8.94 , respectively).

\section{Discussion and conclusion}

In this study - based on leisure trips in the city of Ghent (Belgium) - we have analysed to which extent people travel with their preferred travel mode, and how travel mode consonance and dissonance influence travel satisfaction. The results indicate that mode-specific attitudes have an important impact on the choice of that mode. Attitudes towards a certain mode are significantly more positive for respondents using that mode, compared to respondents using other modes. In order to analyse whether respondents travel with their preferred travel mode, we compared modespecific attitudes towards car use, public transport use, cycling and walking. Doing so, we found that almost half of the respondents (i.e., $48.7 \%$ ) do not use their preferred travel mode. Due to relatively positive attitudes towards cycling, most cyclists seem to travel with their preferred travel mode. Relatively negative attitudes towards public transport use result in a large share of public transport users actually preferring other travel modes. Furthermore, we found that travelling with the preferred travel mode (or otherwise) has an important influence on how satisfied people are with their trips. Respondents travelling with their preferred travel mode (i.e., consonant travellers) seem to experience their trip more positively compared to people travelling with a non-preferred travel mode (i.e., dissonant travellers). For all travel modes, above average travel satisfaction scores were found for consonant travellers, and (except for pedestrians) below average travel satisfaction scores for dissonant travellers. Finally, results indicate that respondents with multimodal preferences do not have higher levels of travel satisfaction compared to respondents with a preference for one mode, even though the former group contains less dissonant travellers than the latter group.

Although results of this study found that respondents travelling with a certain mode have a significantly more positive stance towards that mode compared to people using other modes, it is remarkable that about half of the respondents is not travelling with the preferred travel mode. This might suggest that people do not necessarily have a clear preference for one mode. Although a certain mode might be the preferred one, people might settle with the second-best, somewhat less positively valued, travel mode. On the other hand, this might also suggest that - besides an effect of attitudes on behaviour - travel behaviour can also affect attitudes (see, for instance, Dobson et al., 1978; Golob, 2001; Kroesen et al., 2017; Tardiff, 1977). Attitudes towards a non-preferred travel

\footnotetext{
7 Average scores for respondents with multimodal preferences versus respondents with monomodal preferences are: $-0.08,-0.08,-0.04$ versus $0.01,0.01,0.01$ for positive evaluation, positive deactivation and positive activation, respectively. Mean values of travel satisfaction of respondents with multimodal versus respondents with monomodal preferences are not significantly different from each other at $p<0.05$.
} 
mode of people frequently using this mode might (to a certain extent) improve to fit performed behaviour, possibly to reduce discomfort (Festinger, 1957).

Results from this study also provide valuable insights into the relationship between travel mode choice and travel satisfaction. The fact that consonant travellers have higher levels of travel satisfaction compared to dissonant travellers is in line with recent studies indicating that modespecific attitudes positively affect travel satisfaction when using these modes (De Vos et al., 2016; StLouis et al., 2014; Ye and Titheridge, 2017). Furthermore, we feel that this study provides insights into why travel mode choice affects travel satisfaction. Previous studies found that people using public transport are least satisfied with their trips, while active travel results in the highest levels of travel satisfaction, even in regions with good public transport facilities or limited walking and cycling infrastructure (e.g., De Vos et al., 2016; Legrain et al., 2015; Morris and Guerra, 2015; Páez and Whalen, 2010; St-Louis et al., 2014; Ye and Titheridge, 2017). However, we feel that these differences in travel satisfaction according to the used travel mode can be partly explained by the level of travel mode consonance and dissonance. Although consonant public transport users, for instance, have relatively high travel satisfaction scores, the average travel satisfaction levels of all public transport users is low because of a large share of dissonant public transport users. To a certain extent it can therefore be argued that it is not the chosen travel mode itself that affects travel satisfaction, but whether the chosen mode is the preferred mode.

Besides effects from the chosen travel mode - and whether this mode is the preferred one - on travel satisfaction, it is also possible that satisfying trips with a certain mode positively affect the chance that people will choose this mode for a future trip (Abou-Zeid and Ben-Akiva, 2012; Beirão and Cabral, 2007; De Vos and Witlox, 2017; Lai and Chen, 2011; Reibstein et al., 1980). This effect of travel satisfaction on travel mode choice might also happen indirectly through changes in modespecific attitudes (De Vos et al., 2018). This could result in a positive reinforcement process whereby positively perceived trips improve attitudes towards that mode, which in turn increases the likelihood of continuing to use that mode. On the other hand, unsatisfying trips might also result in a negative reinforcement against continuing the choice of the associated mode, due to negatively affected attitudes. The low average levels of attitudes towards public transport use, the high share of dissonant public transport users and the low satisfaction levels of public transport users suggest such a negative reinforcement process for public transport users. This implies that most public transport users might be forced to use public transport (as they might not have access to a car or that destinations are not within walking and cycling distances). The fact that respondents who do not use the car, cycle or walk have a more positive stance towards these respective modes compared to public transport users' stance towards public transport seems to confirm this. Furthermore, the more positive attitudes towards cycling of non-cyclists compared to car attitudes of car users and especially public transport attitudes of public transport users, suggests that a certain amount of people are forced to use another mode than cycling (e.g., motorised travel due to relatively long travel distances).

Although this study - using a crude measure for capturing travel mode preferences - has provided valuable information concerning the links between mode-specific attitudes, travel mode choice and travel satisfaction, future studies can provide additional insights. As indicated in Section 3.2, considerable attention should be paid to the construction of measures analysing travel mode 
preferences. Mode-specific attitudes should be analysed using measures (i) with a high degree of detail (e.g., by using five- or seven-point scales measuring certain travel mode perceptions), (ii) applied similarly to various travel modes, and (iii) clearly representing a preference for using a certain mode (e.g., by using statements such as: I prefer to bike rather than drive whenever possible). Doing so makes it possible to easily compare attitudes towards different modes, and makes it possible to clearly represent a preference for a certain mode. Furthermore, this also enables the creation of a more detailed measure of travel mode dissonance. Although the binary measure of travel mode dissonance used in this study produces a straightforward - and therefore a useful yet crude estimate of whether respondents are dissonant or not, future studies analysing travel mode dissonance should create a more fine-grained measure that reflects (subtle) differences in the level of dissonance across individuals. This will create better insights into the causes, dimensions and consequences of travel mode dissonance. Furthermore, since no robust conclusions on the causal nature of processes can be drawn from the bivariate analyses performed in this study using crosssectional data, future studies should apply more sophisticated methods - such as a structural equation modelling approach - in combination with the use of longitudinal data in order to improve the identification of causal relationships between travel attitudes, mode choice and travel satisfaction. Furthermore, future studies should also focus on the links between multimodal travel behaviour, multimodal preferences and travel satisfaction (as partly done by Mao et al. (2016) and Molin et al. (2016)). Although we found that a substantial share of respondents (14.0\%) have a preference for more than one mode, we do not know whether these respondents have multimodal travel patterns. Since this study focusses on one trip, we do not know whether these people frequently use two or more travel modes. Furthermore, the fact that most respondents with multimodal preferences $(\mathbf{7 1 . 1 \% )}$ travelled - for their most recent leisure trip - with one of their preferred travel modes but simultaneously do not have higher travel satisfaction levels than respondents with a preference for one mode needs further exploration.

Finally, future studies should also control for personal and environmental factors which can constrain the use of a preferred travel mode, and as a result can affect travel satisfaction. In particular, factors referring to the four proposed elements possibly resulting in travel mode dissonance (i.e., lack of travel-related skills, lack of travel options, presence of travel barriers, and presence of travel habits) should be included into the analysis. Possible variables to be incorporated can be: density, diversity, design, accessibility, quality of infrastructure for active travel, and public transport services representing environmental factors, and age, income, educational level, car availability, possession of driving license, mode familiarity, and overall fitness levels representing personal factors. Doing so, insights can be gained on why, for instance, public transport users and cyclists are mostly dissonant and consonant travellers, respectively. On this regard, qualitative studies (applying in-depth interviews) could also provide valuable information. If the four proposed elements constraining the choice for the preferred travel mode turn out to be accurate, policy measures should focus on reducing travel barriers, improving travel options, making travel-related skills less binding and unfreezing undesired travel habits (e.g., habitual car use). Focusing on public transport, for instance, this could be realized by making public transport routes and schedules more clear to public transport riders, improving comfort and service frequency, increasing public transport services outside urban areas and by providing temporary free public transport passes to habitual car users (creating a new context in which mode decisions happen more consciously (e.g., Fujii and Kitamura, 2003)). Doing so, this could not only increase overall travel satisfaction levels (e.g., Abou-Zeid and Fujii, 2016), but 
could in turn also improve people's subjective well-being and quality of life (De Vos, 2018; De Vos and Witlox, 2017; De Vos et al., 2013; Ettema et al., 2010; Lancée et al., 2017).

\section{Acknowledgements}

The author would like to thank the five anonymous reviewers for their constructive comments and suggestions, making it possible to improve this article. This work was supported by the Research Foundation - Flanders (FWO) under grant 12F2516N.

\section{References}

Aarts, H., Verplanken, B., van Knippenberg, A., 1998. Predicting behaviour from actions in the past: Repeated decision making or a matter of habit? Journal of Applied Social Psychology 28 (15), 13551374.

Abou-Zeid, M., Ben-Akiva, M., 2012. Well-being and activity-based models. Transportation 39 (6), 1189-1207.

Abou-Zeid, M., Fujii, S., 2016. Travel satisfaction effects of changes in public transport usage. Transportation 43 (2), 301-314.

Ajzen, I., 1991. The theory of planned behavior. Organizational Behavior and Human Decision Processes 50 (2), 179-211.

Anable, J., 2005. Complacent car addicts or aspiring environmentalists? Identifying travel behaviour segments using attitude theory. Transport Policy 12 (1), 65-78.

Anable, J., Gatersleben, B., 2005. All work and no play? The role of instrumental and affective factors in work and leisure journeys by different travel modes. Transportation Research Part A 39 (2-3), 163181.

Bagley, M.N., Mokhtarian, P.L., 2002. The impact of residential neighborhood type on travel behavior: a structural equations modeling approach. The Annals of Regional Science 36 (2), 279-297.

Bamberg, S., Ajzen, I., Schmidt, P., 2003. Choice of travel mode in the theory of planned behavior: the roles of past behavior, habit, and reasoned action. Basic and Applied Psychology 25 (3), 175-187.

Beirão, G., Cabral, J.A.S., 2007. Understanding attitudes towards public transport and private car: A qualitative study. Transport Policy 14 (6), 478-489.

Blake, J., 1999. Overcoming the 'value-action gap' in environmental policy: Tensions between national policy and local experience. Local Environment 4 (3), 257-278.

Cao, X., Mokhtarian, P.L., Handy, S.L., 2007. Do changes in neighborhood characteristics lead to changes in travel behavior? A structural equations modeling approach. Transportation 34 (5), 535556.

Cao, X., Mokhtarian, P.L., Handy, S.L., 2009. Examining the impacts of residential self-selection on travel behaviour: a focus on empirical findings. Transport Reviews 29 (3), 359-395.

Cervero, R., Kockelman, K., 1997. Travel demand and the 3Ds: density, diversity and design. Transportation Research Part D 2 (3), 199-219. 
Chen, C., Varley, D., Chen, J., 2011. What Affects Transit Ridership? A Dynamic Analysis involving Multiple Factors, Lags and Asymmetric Behaviour. Urban Studies 48(9) 1893-1908.

De Vos, J., 2018. Analysing the effect of trip satisfaction on satisfaction with the leisure activity at the destination of the trip, in relationship with life satisfaction. Transportation, doi: 10.1007/s11116-0179812-0

De Vos, J., Derudder, B., Van Acker, V., Witlox, F., 2012. Reducing car use: changing attitudes or relocating? The influence of residential dissonance on travel behavior. Journal of Transport Geography 22, 1-9.

De Vos, J., Mokhtarian, P.L., Schwanen, T., Van Acker, V., Witlox, F., 2016. Travel mode choice and travel satisfaction: bridging the gap between decision utility and experienced utility. Transportation 43 (5), 771-796.

De Vos, J., Schwanen, T., Van Acker, V., Witlox, F., 2013. Travel and subjective well-being: a focus on findings, methods and future research needs. Transport Reviews 33 (4), 421-442.

De Vos, J., Schwanen, T., Van Acker, V., Witlox, F., 2015. How satisfying is the Scale for Travel Satisfaction. Transportation Research part F 29, 121-130.

De Vos, J., Schwanen, T., Van Acker, V., Witlox, F., 2018. Do satisfying walking and cycling trips result in more future trips with active travel modes? An exploratory study. International Journal of Sustainable Transportation, doi: 10.1080/15568318.2018.1456580

De Vos, J., Witlox, F., 2016. Do people live in urban neighbourhoods because they do not like to travel? Analysing an alternative residential self-selection hypothesis. Travel Behaviour and Society 4 , 29-39.

De Vos, J., Witlox, F., 2017. Travel satisfaction revisited. On the pivotal role of travel satisfaction in conceptualising a travel behaviour process. Transportation Research Part A 106, 364-373.

de Vries, H., Dijkstra, M., Kuhlman, P., 1988. Self-efficacy: the third factor besides attitude and subjective norm as a predictor of behvioural intentions. Health Education Research 3 (3), 273-282.

dell'Olio, L., Ibeas, A., Cecin, P., 2011. The quality of service desired by public transport users. Transport Policy 18, 217-227.

Dobson, R., Dunbar, F., Smith, C.J., Reibstein, D., Lovelock, C., 1978. Structural models for the analysis of traveler attitude-behavior relationships. Transportation 7 (4), 351-363.

Eagly, A., Chaiken, S., 1993. The Psychology of Attitudes. Harcourt Brace Jovanovich, Fort Worth, TX.

Ettema, D., Gärling, T., Eriksson, L., Friman, M., Olsson, L.E., Fujii, S., 2011. Satisfaction with travel and subjective well-being: development and test of a measurement tool. Transportation Research Part F 14 (3), 167-175.

Ettema, D., Gärling, T., Olsson, L.E., Friman, M., 2010. Out-of-home activities, daily travel, and subjective well-being. Transportation Research Part A 44 (9), 723-732.

Ettema, D., Verschuren, L., 2007. The effect of multitasking on the value of travel time savings. Transportation Research Record 2010, 19-25.

Ewing, R., Cervero, R., 2001. Travel and the built environment: a synthesis. Transportation research Record 1780, 87-114. 
Ewing, R., Cervero, R., 2010. Travel and the built environment. A meta-analysis. Journal of the American Planning Association 76 (3), 265-294.

Festinger, L., 1957. Theory of Cognitive Dissonance. Stanford University Press, Stanford, CA.

Flamm, M., Kaufmann, V., 2006. Operationalizing the concept of motility: a qualitative study. Mobilities 1 (2), 167-189.

Friman, M., Fujii, S., Ettema, D., Gärling, T., Olsson, L.E., 2013. Psychometric analysis of the satisfaction with travel scale. Transportation Research Part A 48, 132-145.

Fujii, S., Kitamura, R., 2003. What does a one-month free bus ticket do to habitual drivers? Transportation 30 (1), 81-95.

Gatersleben, B., Uzzel, D., 2007. Affective appraisals of the daily commute: Comparing perceptions of drivers, cyclists, walkers, and users of public transport. Environment and Behavior 39 (3), 416-431.

Golob, T.F., 2001. Joint models of attitudes and behavior in evaluation of the San Diego I-15 congestion pricing project. Transportation Research Part A 35 (6), 495-514.

Groves, R.M., 1989. Survey errors and survey costs. John Wiley and Sons, New York.

Gärling, T., Axhausen, K.W., 2003. Introduction: habitual travel choice. Transportation 30 (1), 1-11.

Gärling, T., Gillhom, R., Gärling, A., 1998. Reintroducing attitude theory in travel behaviour research. The validity of an interactive interview procedure to predict car use. Transportation, 25 (2), 129-146.

Handy, S.L., Cao, X., Mokhtarian, P.L., 2005. Correlation or causality between the built environment and travel behavior? Evidence from Northern California. Transportation Research Part D 10 (6) 427444.

Handy, S.L., Thigpen, C., 2018. Commute quality and its implications for commute satisfaction: Exploring the role of mode, location, and other factors. Travel Behaviour and Society, doi: 10.1016/j.tbs.2018.03.001

Heinen, E., Maat, K., van Wee, B., 2011. The role of attitudes toward characteristics of bicycle commuting on the choice to cycle to work over various distances. Transportation Research Part A 16 (2), 102-109.

Kahneman, D., Krueger, A.B., 2006. Developments in the measurement of subjective well-being. Journal of Economic Perspectives 20 (1), 3-24.

Kahneman, D., Wakker, P.P., Sarin, R., 1997. Back to Bentham? Explorations of experienced utility. Quarterly Journal of Economics 112 (2), 375-405.

Kamruzzaman, M., Baker, D., Washington, S., Turrell, G., 2013. Residential dissonance and mode choice. Journal of Transport Geography 33, 12-28.

Kaufmann, V., Bergman, M.M., Joye, D., 2004. Motility: mobility as capital. International Journal of Urban and Regional Research 28 (4), 745-756.

Kitamura, R., Mokhtarian, P.L., Laidet, L., 1997. A micro-analysis of land use and travel in five neighborhoods in the San Francisco Bay Area. Transportation 24 (2), 125-158.

Kollmuss, A., Agyeman, J., 2002. Mind the Gap: Why do people act environmentally and what are the barriers to pro-environmental behavior? 8 (3), 239-260. 
Kroesen, M., Chorus, C., 2018. The role of general and specific attitudes in predicting travel behavior - A fatal dilemma? Travel Behaviour and Society 10, 33-41.

Kroesen, M., Handy, S., Chorus, C., 2017. Do attitudes cause behavior or vice versa? An alternative conceptualization of the attitude-behavior relationship in travel behavior modeling. Transportation Research Part A 101, 190-202.

Lai, W.-T., Chen, C.-F., 2011. Behavioral intentions of public transit passengers - The roles of service quality, perceived value, satisfaction and involvement. Transport Policy 18 (2), 318-325.

Lancée, S., Veenhoven, R., Burger, M., 2017. Mood during commute in the Netherlands: What way of travel feels best for what kind of people? Transportation Research Part A 104, 195-208.

Legrain, A., Eluru, N., El-Geneidy, A., 2015. Am stressed, must travel: The relationship between mode choice and commuting stress. Transportation Research Part F 34, 141-151.

Lorenc, T., Brunton, T., Oliver, S., Oliver, K., Oakley A., 2008. Attitudes to walking and cycling among children, young people and parents: a systematic review. Journal of Epidemiology and Community Health 62 (10), 852-857.

Malokin, A., Circella, G., Mokhtarian, P.L., 2015. How do activities conducted while commuting influence mode choice? Testing public transportation advantage and autonomous vehicle scenarios. Paper presented at the 94th Annual Meeting of the Transportation Research Board.

Mao, Z., Ettema, D., Dijst, M., 2016. Commuting trip satisfaction in Beijing: exploring the influence of multimodal behavior and modal flexibility. Transportation Research Part A 94, 592-603.

Mishra, G.S., Mokhtarian, P.L., Widaman, K.F., 2015. An empirical investigation of attitudes toward waiting on the part of Northern California commuters. Travel Behaviour and Society 2 (2), 78-87.

Mokhtarian, P.L., Papon, F., Goulard, M., Diana, M., 2015. What makes travel pleasant and/or tiring? An investigation based on the French National Travel Survey. Transportation 42 (6), 1103-1128.

Molin, E., Mokhtarian, P.L., Kroesen, M., 2016. Multimodal travel groups and attitudes: A latent class cluster analysis of Dutch travelers. Transportation Research Part A 83, 14-29.

Morris, E.A., Guerra, E., 2015. Mood and mode: does how we travel affect how we feel? Transportation 42 (1), 25-43.

Olsson, L.E., Gärling, T., Ettema, D., Friman, M., Fujii, S., 2013. Happiness and satisfaction with work commute. Social Indicators Research 111 (1), 255-263.

Páez, A., Whalen, K., 2010. Enjoyment of commute: A comparison of different transportation modes. Transportation Research Part A 44 (7), 537-549.

Pooley, C.G., Horton, D., Scheldeman, G., Mullen, C., Jones, T., Tight, M., Jopson, A., Chisholm, A., 2013. Policies for promoting walking and cycling in England: A view from the street. Transport Policy 27, 66-72.

Reibstein, D.J., Lovelock, C.H., Dobson, R.P., 1980. The direction of causality between perceptions, affect, and behavior: an application to travel behavior. Journal of Consumer Research 6 (4), 370-376.

Saelens, B.E., Sallis, J.F., Black, J.B., Chen, D., 2003a. Neighbourhood-based differences in physical activity: an environment scale evaluation. American Journal of Public Health 93 (9), 1552- 1558. 
Saelens, B.E., Sallis, J.F., Lawrence D.F., 2003b. Environmental correlates of walking and cycling: Findings from the transportation, urban design, and planning literatures. Annals of Behavioral Medicine 25 (2), 80-91.

Sallis, J.F., Frank, L.D., Saelens, B.E., Kraft, M.K., 2004. Active transportation and physical activity: opportunities for collaboration on transportation and public health research. Transportation Research Part A 38 (4), 249-268.

Schwanen, T., Mokhtarian, P.L., 2005. What affects commute mode choice, neighbourhood physical structure or preferences toward neighborhoods? Journal of Transport Geography 13 (1), 83-99.

Shliselberg, R., Givoni, M., 2018. Motility as a policy objective. Transport Reviews 38 (3), 279-297.

Singleton, P.A., 2018. Walking (and cycling) to well-being: Modal and other determinants of subjective well-being during the commute. Travel Behaviour and Society, doi: 10.1016/j.tbs.2018.02.005

Smith, O., 2017. Commute well-being differences by mode: Evidence from Portland, Oregon, USA. Journal of Transport \& Health 4, 246-254.

St-Louis, E., Manaugh, K., van Lierop, D., El-Geneidy, A., 2014. The happy commuter: a comparison of commuter satisfaction across modes. Transportation Research Part F 26, 160-170.

Tardiff, T.J., 1977. Causal inferences involving transportation attitudes and behavior. Transportation Research 11 (6), 397-404.

Van Acker, V., van Wee, B., Witlox, F., 2010. When transport geography meets social psychology: toward a conceptual model of travel behaviour. Transport Reviews 30 (2), 219-240.

van Lierop, D., Badami, M.G., El-Geneidy, A., 2018. What influences satisfaction and loyalty in public transport? A review of the literature. Transport Reviews 38 (1), 52-72.

van Wee, B., Holwerda, H., van Baren, R., 2002. Preferences for Modes, Residential Location and Travel Behaviour: the Relevance for Land-Use Impacts on Mobility. European Journal of Transport and Infrastructure Research 2 (3/4), 305-316.

Verplanken, B., Aarts, H., van Knippenberg, A., 1997. Habit, information acquisition, and the process of making travel mode choices. European Journal of Social Psychology 27 (5), 539-560.

Ye, R., Titheridge, H., 2017. Satisfaction with the commute: The role of travel mode choice, built environment and attitudes. Transportation Research Part D 52B, 535-547.

Zhu, J., Fan, Y., 2018. Commute happiness in Xi'an, China: Effects of commute mode, duration, and frequency. Travel Behaviour and Society 11, 43-51. 